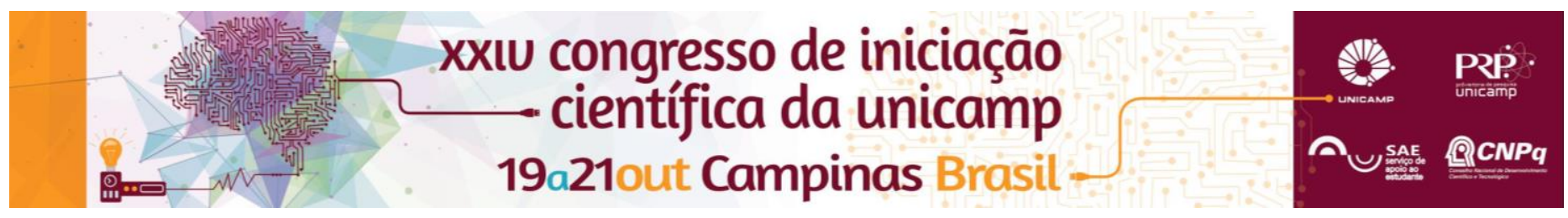

\title{
Qualidade de vida em pacientes com tumores epiteliais antes e após tratamento
}

\author{
Luiz Alípio de Souza Júnior*, Fernanda Ometto, Renata Ferreira Magalhães.
}

\section{Resumo}

O câncer de pele não melanoma é a neoplasia mais prevalente na população brasileira e, apesar da baixa mortalidade, traz grande morbidade e prejuízo na qualidade de vida (QV) dos pacientes. O objetivo deste trabalho foi avaliar a QV dos pacientes com este diagnóstico e a importância do uso, na prática clínica, de instrumentos que medem seu impacto. Foram selecionados aleatoriamente 103 pacientes adultos com diagnóstico de câncer de pele não melanoma, que aceitaram responder questionários de avaliação da QV. Os resultados mostraram dados epidemiológicos compatíveis com a literatura. Ambos os questionários evidenciaram impacto moderado a grave na QV de cerca de $20 \%$ dos pacientes, mostrando-se instrumentos de auxílio à investigação dos efeitos da doença sobre o indivíduo.

Palavras-chave: Qualidade de vida, Tumores epiteliais, SKINDEX.

\section{Introdução}

O câncer de pele não melanoma compõe $25 \%$ de todos os tumores malignos registrados no país, sendo o de maior incidência e menor mortalidade. Apesar disso, traz grande morbidade e prejuízo à qualidade de vida $(\mathrm{QV})$ dos pacientes. A exposição solar é o principal fator de risco associado a este tipo de câncer, sendo as áreas fotoexpostas as regiões mais acometidas. $\mathrm{O}$ tratamento de escolha é a cirurgia, mas radioterapia, crioterapia, infiltração intralesional e tratamento com tópicos podem ser indicados. Muitas vezes o tratamento pode ser mutilante, inestético ou incapacitante, afetando sobremaneira a qualidade de vida do paciente. Há vários instrumentos para medir a QV nas mais diferentes esferas da saúde. Os instrumentos podem ser de avaliação genérica ou específica de uma doença ou condição (como psoríase, dermatite atópica, câncer de mama). O objetivo deste trabalho foi avaliar a qualidade de vida dos pacientes com diagnóstico de câncer de pele não melanoma e a importância do uso, na prática clínica, de instrumentos que medem seu impacto.

\section{Resultados e Discussão}

Foram selecionados aleatoriamente 103 pacientes ambulatoriais com diagnóstico de carcinomas basocelular (CBC) ou espinocelular (CEC). A coleta de dados epidemiológicos e clínicos foi realizada por interrogatório simples ou revisão de prontuário. Os pacientes preencheram questionários autoaplicáveis sobre qualidade de vida (DLQI, SKINDEX, HADS), sem intervenção do avaliador. As respostas de cada indivíduo foram traduzidas em valores numéricos e classificadas de acordo com a correção proposta para cada questionário utilizado.

O perfil epidemiológico do estudo mostrou predominância do sexo masculino (53,4\%), da faixa etária acima de 65 anos $(72,8 \%)$, da etnia branca $(80,6 \%)$ e do grau de escolaridade "ensino fundamental incompleto" (29,1\%). Quanto ao diagnóstico, observou-se $62(60,2 \%)$ casos de CBC, 15 (14,6\%) de CEC e 26 (25,2\%) indivíduos com ambos diagnósticos. Essa casuística mostra-se compatível com os dados da literatura.

Pela categorização do DLQI, tiveram efeito leve, moderado ou grave sobre a QV, respectivamente, $26(25,3 \%), 14$ $(13,6 \%)$ e $9(8,7 \%)$ participantes. A doença cutânea não implicava efeitos na QV de 51 indivíduos (49,5\%).

Pelo questionário HADS, no âmbito da Ansiedade, 10 $(9,7 \%)$ indivíduos obtiveram somatória borderline e 11 pessoas $(10,7 \%)$ tiveram resultado anormal, sugestivo de transtorno de ansiedade, sendo $74(71,9 \%)$ indivíduos com pontuação normal. Quanto aos sintomas de Depressão, evidenciou-se resultado normal, borderline e anormal (sugestivo de transtorno do humor) para 77 (74,9\%), 9 $(8,7 \%)$ e $9(8,7 \%)$ participantes, respectivamente. A análise das diferentes esferas, pelo SKINDEX, está representada na Figura 1.

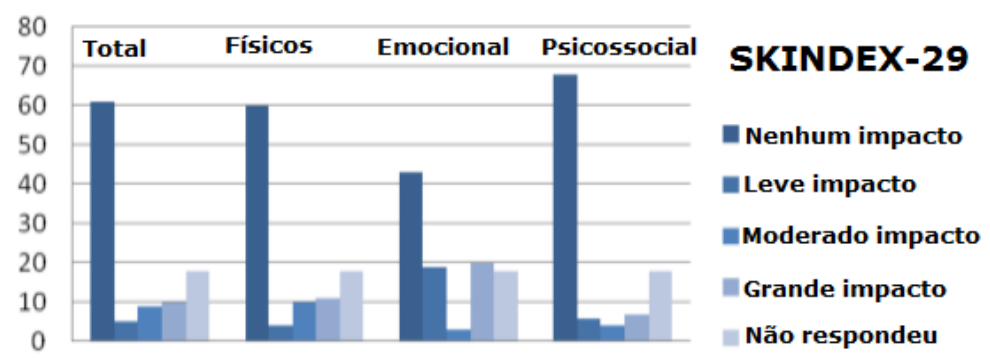

Figura 1 - Resultados Skindex-29.

Os três questionários aplicados mostraram impacto de moderado a grave na qualidade de vida de cerca de $20 \%$ dos pacientes investigados, sobretudo na esfera emocional, incluindo sintomas de ansiedade e depressão. Acerca do elevado número de pacientes com pequena repercussão, encontram-se possíveis vieses na seleção da amostra em nível de atenção terciária, com capacidade de prover tratamentos resolutivos; na dependência do preenchimento adequado dos questionários sobre a capacidade cognitiva dos participantes, de baixa escolaridade e idade avançada; e no uso de questionários validados para dermatologia geral sobre um diagnóstico específico, de câncer de pele não melanoma.

\section{Conclusões}

O estudo permite concluir que o diagnóstico e tratamento do câncer de pele não melanoma afetaram significativamente a qualidade de vida de $20 \%$ dos pacientes avaliados, e que os questionários aplicados podem ser utilizados como complementação da consulta e da percepção do médico quanto às dificuldades enfrentadas pelos pacientes e seus familiares.

1- Paula, HR; Haddad, A; Weiss, MA; Dini, GM; Ferreira, LM. Translation, cultural adaptation and validation of the American Skindex-29 quality of life índex. An Bras Dermatol. 2014; 89(4): 600-7.

2- Lee, EH, M.D. et al. A systematic review of patient-reported outcome instruments of nonmelanoma skin cancer in the dermatologic population. J Am Acad Dermatol. 2013; 69(2): 59-67. 